\title{
Investigational and Experimental Drugs to Treat Obsessive-Compulsive Disorder
}

This article was published in the following Dove Press journal:

Journal of Experimental Pharmacology

\section{Giacomo Grassi (D) \\ Chiara Cecchelli \\ Luisa Vignozzi (D) \\ Silvia Pacini}

Neuroscience Department, Brain Center Firenze, Florence, Italy
Correspondence: Giacomo Grassi

Brain Center Firenze, Viale Belfiore 36 ,

Florence 50144, Italy

Email giacomograssimd@gmail.com

\begin{abstract}
Treatment-resistance is a frequent condition for obsessive-compulsive disorder (OCD). Over the past decades, a lot of effort has been made to address this issue, and several augmentation strategies of serotonergic drugs have been investigated. Antidopaminergic drugs are considered the first choice as augmentation strategy for treatment-resistant OCD patients, but they seem to work only for a subset of patients, and none of them have been officially approved for OCD. Recently, the role of glutamate and inflammation in OCD pathophysiology clearly emerged, and this has led to several investigations on glutamatergic and anti-inflammatory agents. Results seem promising but still inconclusive. Probiotic interventions (considered to modulate the immune systems and the brain activity) are gaining attention in several psychiatric fields but are still at their early stages in the OCD field. Research on new treatment approaches for OCD is moving forward, and more than one hundred interventional trials are ongoing around the world. While the vast majority of these trials involve neuromodulation and psychotherapeutic approaches, only a small proportion (around 20\%) involve the investigation of new pharmacological approaches (tolcapone, nabilone, psilocybin, troriluzole, nitrous oxide, rituximab, naproxen, and immunoglobulins). Here, we provide a comprehensive review of investigational and experimental drugs to treat OCD.
\end{abstract}

Keywords: OCD, glutamate, immune system, inflammation, probiotics, pharmacotherapy

\section{Introduction}

Obsessive-compulsive disorder (OCD) is a neuropsychiatric disorder with a lifetime prevalence of $1-2 \%$ in the general population and is the fourth most frequent psychiatric disorder. ${ }^{1}$ The story of OCD medications is relatively recent. In the mideighties, clomipramine (the most selective serotonergic drug among the tricyclic antidepressants) was seen to have a specific anti-obsessive effect compared to other antidepressants (with more noradrenergic effects). ${ }^{2}$ From that discovery, in subsequent years, the role of the serotonergic system in OCD pathophysiology has become the center of investigation for the subsequent years and selective serotonin reuptake inhibitors (SSRIs) rapidly gained the role of first-line treatments for OCD patients. $^{3,4}$ Although SRIs changed the natural history and treatment trajectory of OCD patients, up to $40-60 \%$ of patients, still do not respond to these treatments ${ }^{5,6}$ Consequently, the mid-nineties research moved to investigating augmentation strategies for OCD. From that period on, several trials emerged in which antidopaminergic agents (eg, haloperidol, risperidone, etc.) were added to SRIs treatment. The results proved the effectiveness of this augmentation strategy, initially and mainly in tic-related and/or poor-insight OCD patients, but then in a broader cohort of 
treatment-resistant patients. ${ }^{7}$ After more than 20 years, as shown by recent meta-analyses, several antidopaminergic agents have been confirmed to be significantly superior to placebo as augmentation to SRIs in resistant-OCD patients. ${ }^{8}$ However, this is true, on average, for only onethird of resistant patients. ${ }^{7}$ Therefore, the research for new treatments beyond current guidelines is still mandatory. ${ }^{5,6}$

In more recent years, pathophysiological studies moved beyond serotonin and dopamine and increasingly and consistently showed glutamate and inflammatory involvement in OCD pathophysiology.

The aim of this paper is to review current available data on investigational and experimental drugs for treating OCD. In the first sections, we will specifically focus on glutamate and anti-inflammatory agents since they represent the most promising areas of research and because we already have controlled trials that can inform us about their future role in the treatment of OCD. In the second section, we will focus on medications under investigation and for which there is still a lack of controlled studies.

\section{Methods}

A PubMed search was conducted using the terms "obsessive-compulsive disorder", "OCD treatment", "medications", "augmentation", "glutamate", "OCD medications" "glutamate system", "glutamatergic agents", "inflammation", "PANDAS", "PANS", "anti-inflammatory agents", "microbioma/microbiota", "probiotics". We also looked for still ongoing trials on the website www.clinicaltrials. gov (last update mid-September 2020). To conduct this research, the search term used was "obsessive-compulsive disorders". The search filter used was "recruiting, not yet recruiting, active-not recruiting and enrolling by invitation" in order to find the still ongoing and non-published trials.

\section{Glutamatergic Agents in OCD}

A glutamatergic dysfunction in OCD patients emerged in the last years and was supported by preclinical, imaging, and genetic studies. Functional studies converged on the presence of a hyperglutamatergic state in the so-called cortico-striatal-thalamo-cortical circuit of OCD patients'. ${ }^{9-14}$ Recent studies on both pediatric and adult OCD patients demonstrated a link between the response to fear-extinction during cognitive-behavioral therapy and glutamate levels. ${ }^{15-17}$ However, establishing a clear relation between glutamatergic dysfunction and OCD and understanding its exact functional meaning, is not an easy task, for several reasons. Firstly, glutamatergic neurons are present in almost all brain circuitries and are therefore difficult to specifically localize a glutamatergic dysfunction in a specific brain area. ${ }^{18}$ Secondly, while most studies converged on a hyper-glutamatergic state in OCD patients, it is noted that also pro-glutamatergic agents show some positive effects for OCD symptoms. ${ }^{19}$ Summarized here is current evidence on glutamatergic agents for OCD.

\section{Ketamine}

In recent years, ketamine (a non-competitive antagonist of the N-methyl-D-aspartate (NMDA) receptor, usually administered intravenously) gained much attention due to its rapid-onset antidepressant effect on treatment-resistant depressed patients. ${ }^{20}$ This interest grew up when subsequent studies indicated the short-term effect reported in the first infusive trials could be sustained with repeated doses. ${ }^{20}$ After these reports, some researchers studied ketamine also for OCD. In fact, early reports demonstrated rapid-onset but short-term anti-obsessional effects of a single intravenous dose of ketamine infusion. ${ }^{21-23}$ Furthermore, a randomized cross-over trial, conducted by the group of Carolyn Rodriguez at the Stanford University on 15 OCD patients, showed the significant antiobsessional effect of a ketamine's single-infusion both immediately after the first infusion and after a 1 week follow-up. ${ }^{24}$ Interestingly, their study revealed the antiobsessional effect (almost 50\% of responders) was not driven by the ketamine's antidepressant effect, but its mechanism of action appeared to be related to GABA reduction in the medial cortex. ${ }^{25}$ In order to extend the observed anti-obsessional effects of ketamine, the same group investigated two different approaches in two subsequent studies: adding intensive cognitive behavioral therapy (CBT) (10 sessions in 2 weeks after ketamine infusion) or adding memantine after a ketamine infusion. Results of these studies showed that ketamine's antiobsessional effects in responder patients are sustained over time when adding CBT but not when adding memantine. ${ }^{26,27}$

\section{Rapastinel (GLYX-I3)}

Rapastinel (formal name GLYX-13) is a partial agonist at the glycine site of the glutamate NMDA receptor and, as is the case for ketamine, it is usually administered intravenously. Rapastinel has been shown to have both an antidepressant and a cognitive-enhancing activity without the typical side effects seen with ketamine. ${ }^{28}$ Rodriguez et al 
showed a rapid but short-term improvement on OCD, anxiety, and depressive symptoms in a small sample of treatment-resistant OCD patients. ${ }^{29}$ Interestingly, in a separate paper on the same OCD sample, the rapastinel's effect, contrary to what had been observed for ketamine, appeared to be correlated to a reduction of the BrainDerived Neurotrophic Factor (BDNF). ${ }^{30}$

\section{Memantine}

Memantine is non-competitive NMDA receptor blockers that have been approved for the treatment of Alzheimer's disease. Compared to ketamine, memantine exerts a weak block of the ion channel pore of the NMDA receptor. ${ }^{19}$ Due to its glutamate-modulating properties and its tolerability, memantine has been investigated for treatmentresistant OCD across several studies by different research groups. After some initial positive case studies and small open trials, between 2013 and 2018, three independent placebo-controlled trials showed a significantly positive effect on OCD symptoms when used as an addition to SRIs medications. ${ }^{31-41}$ A recent meta-analysis in 2019 put together these controlled studies and confirmed the efficacy of memantine in both moderate and severe treatment-resistant OCD. ${ }^{42}$ Thus, memantine is one of the most promising glutamatergic agents for the treatment of OCD. Further multicenter trials are warranted to extend its use to the resistant-OCD population.

\section{$\mathrm{N}$-Acetylcysteine (NAC) and L-Carnosine} Meanwhile, NAC (a precursor of the amino acid cysteine) and 1-carnosine (a dipeptide made up of the two amino acids beta-alanine and histidine) are usually thought to have in common only an antioxidant activity, they also share an interesting glutamate-modulating activity that has been investigated for the treatment of different psychiatric disorders. ${ }^{43,52-54}$ NAC modulates glutamatergic transmission by the cystine-glutamate antiporter, while 1-carnosine reduces glutamatergic activity by upregulating the glutamate transporter $1 .{ }^{43,52}$ For the OCD spectrum, NAC showed clear benefits in placebo-controlled trials for both trichotillomania and excoriation disorder. ${ }^{44,45}$ However, its usefulness for OCD patients is still controversial. In fact, of the 5 available controlled trials of NAC augmentation of SRIs for treatment-resistant OCD patients, 3 showed positive results while 2 showed negative results. ${ }^{46-50}$ Of note, a recent small open trial on pediatric OCD patients showed some initial positive effects of NAC on OCD symptoms. ${ }^{51}$ On the other hand, L-carnosine has been less investigated for $\mathrm{OCD}$, but the only available controlled trial (1 $\mathrm{g}$ of L-carnosine as add on to fluvoxamine) showed good results. ${ }^{55,56}$

\section{Lamotrigine and Topiramate}

Lamotrigine and topiramate are two inhibitors of the glutamate AMPA (alpha-amino-3-hydroxy-5-methyl-4-isoxazole-propionate) receptors. $^{57}$ Lamotrigine showed a significant effect on OCD symptoms in two different placebo-controlled trials as add-on to SRIs. It also showed some effectiveness on OCD symptoms in patients with comorbid schizophrenia and OCD (the so-called "schizoobsessive" population). ${ }^{58-60}$ However, a recent naturalistic study on bipolar patients showed the onset of de-novo OCD symptoms in patients treated with lamotrigine. For most of these patients, OCD symptoms disappeared after 1 month of lamotrigine discontinuation. ${ }^{61}$ On the other hand, topiramate effects on OCD are still inconclusive. Of the 3 available controlled trials, 2 has been negative and only the first one resulted positive. ${ }^{62-64}$

\section{Other Glutamatergic Agents}

Some other glutamatergic agents have been investigated for OCD: three modulators of the glycine-cite in the NMDA receptors (glycine, d-cycloserine, and sarcosine) and riluzole, a glutamate release inhibitor and glutamate glial uptake stimulator. While glycine showed a clear lack of anti-OCD effects and poor tolerability in controlled trials ${ }^{65} \mathrm{~d}$-cycloserine (DCS) data is more controversial. DCS has gained attention as an augmentation strategy for exposure and response prevention therapy due to its ability to enhance fear extinction in animal models. However, controlled trials on adults and children with OCD produced mixed results, and recent meta-analyses showed minimal benefits. ${ }^{66-69}$ Sarcosine showed some promising results in an open trial, but with a small sample size. ${ }^{70}$ Finally, riluzole showed good results in only one of the three available controlled trials. ${ }^{71-73}$

\section{Anti-Inflammatory Agents in OCD}

Today, we can talk about the so-called "immunopsychiatry", since the role of autoimmunity and inflammation has been recognized to play a role in the pathophysiology of several psychiatric disorders including depression and schizophrenia. ${ }^{74}$ Autoimmunity was initially implicated in the OCD pathophysiology in the early nineties, with the socalled pediatric autoimmune neuropsychiatric disorder associated with group A beta-hemolytic streptococcus 
(GABHS) (PANDAS), then renamed pediatric acute neuropsychiatric syndrome (PANS) ${ }^{75-78}$ After that, a putative role of neuroinflammation and autoimmunity in OCD pathophysiology emerged also in adults. Autoimmune disorders, such as lupus erythematosus and multiple sclerosis, are highly prevalent in OCD patients, and nationwide studies on OCD and their healthy relatives reported up to $43 \%$ of comorbid autoimmune diseases. ${ }^{79-81}$ Also, several studies and recent meta-analyses consistently showed a fivefold higher rate of anti-basal ganglia antibodies in OCD patients compared to controls. ${ }^{78}$ Finally, while the presence of cytokines levels abnormalities in OCD patients is still controversial according to the most recent metaanalyses, ${ }^{82}$ a recent paper shows the presence of inflammation markers in the adult OCD brain (specifically within the cortico-striatal-thalamo-cortical regions supposed to be involved in OCD pathophysiology). ${ }^{83}$ Despite early investigations suggested a positive effect of antibiotics on PANS patients, current literature did not support their use but showed promising effects of the non-steroidal antiinflammatory drugs (NSAID). ${ }^{84,85}$ Thus, antiinflammatory agents have also been investigated on adults with OCD. Here, we will review current literature on antiinflammatory agents for adults with OCD.

\section{Celecoxib}

Celecoxib is an NSAID that exerts its anti-inflammatory activity by inhibiting the cyclooxygenase-2 (COX-2) enzyme. COX-2 inhibitors showed a protective effect on glutamate-mediated neural death and they exert an antiinflammatory action by inhibiting the production of proinflammatory cytokines (especially TNF- $\alpha$ and IL-6). ${ }^{86,87}$ Celecoxib showed an antidepressant effect, correlated to IL-6 levels reduction, in a controlled trial on patients with major depressive disorder. ${ }^{88}$ Two double-blind controlled trials by two different research groups in the same country investigated the effectiveness of celecoxib $400 \mathrm{mg}$ augmentation of SSRIs (fluoxetine and fluvoxamine, respectively) for 8 weeks vs placebo. ${ }^{89,90}$ In both trials, celecoxib was well tolerated and was found to be superior to placebo. However, results of both studies have serious limitations considering in both cases SSRIs were administered at a low dose (under the recommended ones) and for a nonadequate treatment period before adding celecoxib. This fact poses difficulties in distinguishing a direct effect of celecoxib vs a carry-over effect of SSRIs. ${ }^{89,90}$ Thus, despite these preliminary results are intriguing in the view of an inflammation-mediated pathophysiology of
OCD, further and larger multicenter trials are needed to generalize these results.

\section{Minocycline}

Minocycline is a tetracycline antibiotic with both antiglutamatergic and anti-inflammatory activities. ${ }^{91}$ While the first open study on OCD patients was negative a recent double-blind controlled study on more than hundred OCD patients showed a significant anti-obsessional effect when added to fluvoxamine. ${ }^{92,93}$

\section{Probiotics}

Probiotics can help in regulating the human immunological system and the brain through the so-called "microbiota-gutbrain axis" (the set of hormonal, immunological, and neural connections between the brain and the gut-microbiota). ${ }^{94,98-101}$ A putative role of the microbiota-gut-brain axis has already been suggested for several psychiatric disorders (depression, ADHD, autism spectrum disorders, bipolar disorder, psychosis, and post-traumatic stress disorder). ${ }^{95-97}$ However, this field of research is still at its early stages in the world of OCD research. In 2020, a group of researchers showed that the natural compulsive-like behavior in the deer mouse is associated with altered gut microbiota composition. ${ }^{102}$ In 2018, an Italian group of researchers demonstrated that children with the PANS and PANDAS showed an altered bacterial community structure, in particular showing the presence of a high increase in Bacteroidetes. ${ }^{103}$ Interestingly, a recent Canadian study was the first to show that adult OCD patients have less richness/ evenness of gut microbiota compared to controls and in particular they display a lower presence of three butyrateproducing genera (namely Oscillospira, Odoribacter, and Anaerostipes). ${ }^{95}$ These latter results are of special interest since butyrate-producing species seem to have an antiinflammatory effect on human immunological state. ${ }^{95}$ To the best of our knowledge, there are still no available trials on probiotics interventions for OCD patients. Only studies on animal models of OCD and on healthy volunteers with OC symptoms showed intriguing results. ${ }^{104,105}$ According to our research on clinicaltrials.gov (mid-September 2020), there is an ongoing trial on the probiotic formula Lactobacillus Helveticus and Bifidobacterium Longum (two probiotic agents that showed anxiolytic properties on human studies).

\section{Drugs Under Investigation}

In the following section, we will report the results of a systematic search on clinicaltrials.gov website database (updated at mid-September 2020) in order to propose an 
overview of the ongoing drugs under investigations for OCD. The search resulted in a total of 129 recorded studies. Out of these, 113 studies involved interventional treatment arms. However, only $19.5 \%$ involved pharmacological treatments. The remaining $80.5 \%$ of the trials involved psychological treatments (internet-based psychotherapy, new cognitive-behavioral and mindfulnessbased protocols) and neuromodulation techniques (deep brain stimulation (DBS), transcranial magnetic stimulation (TMS), transcranial direct current stimulation (tDCS), and other neuromodulation interventions). These search results are interesting since they point out the fact that in the last years the pharmacological research for new treatments for OCD became the minority part of this field. Moreover, just a few of the pharmacological treatments investigated are "really" new agents or agents without previous investigations in the OCD field (here we will present these latter agents).

Considering that for most of the drugs presented in this section there are still no controlled trials available, we will report the rational for their investigation in OCD treatment and a brief summary of their proposed mechanisms of action (for a summary see Table 1).

\section{Tolcapone}

Catechol-O-methyltransferase (COMT) is an enzyme implicated in the degradation of catecholamines (eg, noradrenaline, dopamine) by transferring a methyl group to their hydroxyl group. ${ }^{106}$ Several studies implicated COMT in the pathophysiology of psychiatric disorders such as schizophrenia, bipolar disorders, Parkinson's disease, depression, ADHD, addictions and also OCD. ${ }^{107}$ The COMT gene is present on chromosome 22 q11 and several polymorphisms have been reported. Val158Met ( $G$ to A) polymorphism is the most studied and clinically important. ${ }^{108}$ Substitution of Val by Met at 158th position reduces COMT activity. Since COMT inactivates dopamine in the prefrontal cortex, subjects with the lowactivity allele showed lower COMT and higher dopamine levels. ${ }^{109-112}$ COMT gene Val158Met polymorphism has been consistently linked to several psychiatric disorders such as schizophrenia, panic disorders, bipolar disorder, ADHD, suicide, and addiction disorders. ${ }^{113}$ In the OCD field,

Table I Drugs Under Investigations for OCD

\begin{tabular}{|c|c|c|c|}
\hline & Proposed Mechanism of Action for OCD & Trial Design & $\begin{array}{l}\text { Drug Dose and Duration of } \\
\text { Treatment }\end{array}$ \\
\hline Tolcapone & COMT-inhibitor & QB cross-over & Tolcapone $200 \mathrm{mg} / 2$ weeks \\
\hline Nabilone & $\mathrm{CBI}$ receptor agonist & $\begin{array}{l}\text { Randomized, two arms: nabilone } \\
\text { "alone" vs nabilone + ERP }\end{array}$ & Nabilone I mg/4 weeks \\
\hline Psilocybin & $5-\mathrm{HT}_{1 \mathrm{~A}}$ and $5-\mathrm{HT}_{2 \mathrm{~A} / 2 \mathrm{C}}$ receptors agonist & $\begin{array}{l}\text { QB active-placebo-controlled } \\
\text { (Niacine } 250 \mathrm{mg} \text { ) }\end{array}$ & $\begin{array}{l}\text { Psilocybin } 0.25 \mathrm{mg} / \mathrm{Kg} / \mathrm{single} \\
\text { dose }\end{array}$ \\
\hline $\begin{array}{l}\text { Troriluzole (BHV- } \\
4157)\end{array}$ & $\begin{array}{l}\text { Augmenting the expression and function of } \\
\text { excitatory amino acid transporters (ie, EAAT2) }\end{array}$ & DBPC & Troriluzole $140 \mathrm{mg} / \mathrm{I} 2$ weeks \\
\hline Nitrous oxide gas & $\begin{array}{l}\text { Glutamate NMDA and AMPA receptors antagonist/ } \\
\text { Low voltage calcium channels inhibitor }\end{array}$ & QBPC & $\begin{array}{l}50 \% \text { oxygen }+50 \% \text { nitrous } \\
\text { oxide admixture } 60 \text { minutes }\end{array}$ \\
\hline Rituximab & Antibodies against $C D 20$, cluster of differentiation & Open label & $1000 \mathrm{mg} / \mathrm{single}$ dose \\
\hline $\begin{array}{l}\text { Naproxen (for } \\
\text { PANDAS/PANS) }\end{array}$ & Non selective COX-I and COX-2 inhibitor & QBPC & $10 \mathrm{mg} / \mathrm{Kg} / 8$ weeks \\
\hline $\begin{array}{l}\text { Octagam } 5 \% \text { (for } \\
\text { PANDAS/PANS) }\end{array}$ & Immunoglobulines & Open label & $\mathrm{Ig} / \mathrm{Kg}(6$ infusions) $/ 18$ weeks \\
\hline Pregabalin & $\mathrm{Ca}^{2+}$ channels modulation & QBPC & Up to $600 \mathrm{mg} / 8$ weeks \\
\hline $\begin{array}{l}\text { Ondansetron (for } \\
\text { tic-related } O C D \text { ) }\end{array}$ & $5 \mathrm{HT}_{3}$ receptors antagonist & QBPC & $24 \mathrm{mg} / 4$ weeks \\
\hline
\end{tabular}

Abbreviations: OCD, obsessive-compulsive disorder; DBPC, double-blind placebo-controlled; QBPC, quadruple blind placebo controlled; COMT, catecholO-methyltransferase; 5HT, serotonin; CBIR, cannabinoid receptor type I; ERP, exposure and response prevention; EAAT2, excitatory amino acid transporter 2; NMDA, $\mathrm{N}$-methyl-D-aspartate receptor; AMPA, $\alpha$-amino-3-hydroxy-5-methyl-4-isoxazolepropionic acid receptor; COX-I/2, cyclo-oxygenase. 
investigation of Val158Met polymorphism produced mixed results across studies, but in recent years evidence has become more consistent in favor of a link between OCD and this polymorphism. ${ }^{108}$ Also, several studies suggest that COMT allelic variants might have an effect on cognitive domains such as memory, executive functions, and decision-making. ${ }^{108}$ Dysfunctional decision-making and executive functions have been associated with OCD and some of these have been proposed as OCD endophenotype. ${ }^{7,114}$ Finally, dopaminergic circuitries dysfunction has been highly replicated across OCD studies and dopaminergic agents have been proposed as augmentation strategies for almost ten years. ${ }^{115}$

Tolcapone is a selective and reversible COMT inhibitor and is widely used in the treatment of Parkinson disease. ${ }^{116}$ Tolcapone inhibits the methylation of levodopa preventing the formation of its metabolite methyldopa (a competitor of levodopa in crossing the blood-brain barrier). ${ }^{116}$ By doing this, tolcapone enhances the brain availability of levodopa. ${ }^{116}$

The Chicago University is running a randomized controlled trial in order to investigate the putative therapeutic effects of tolcapone in a clinical sample of OCD subjects. According to the trial status in clinicaltrials.gov website (mid-September 2020), the trial is yet recruiting participants.

\section{Nabilone}

An anti-obsessional and anti-anxiety effect of cannabis has been reported anecdotally by some OCD patients who smoke cannabis. ${ }^{117}$ Interestingly, the endocannabinoid system could be relevant to OCD pathophysiology. Indeed, the type 1 cannabinoid receptors (CB1R) are highly expressed in several brain areas involved in OCD (eg, prefrontal cortex, amygdala, and the striatum) and preclinical studies highlighted their role in fear-extinction and the balance between goal-direct vs habitual behaviors (two cognitive functions implicated in OCD pathophysiology). ${ }^{117,118}$ Furthermore, cannabinoids also proved to relive anxiety and compulsive behaviors in animal models. ${ }^{117}$

In the OCD field, two case reports showed that dronabinol (tetrahydrocannabinol, THC), an agonist at central cannabinoid CB1 receptors, improved OCD symptoms in treatment-resistant patients, and a recent case report showed the efficacy of medical cannabis in a 22 -year-old men with both OCD and comorbid depression. ${ }^{119}$ These reports are in line with current literature on Tourette syndrome showing positive effects on both tics and comorbid
OCD symptoms of several forms of cannabis agents (THC, cannabis extracts, and flowers). ${ }^{119}$

Nabilone is a synthetic cannabinoid that is thought to be a CB1R agonist. Recently, an open label two arms trial (sponsored by the New York State Psychiatric Institute) investigated the effects of nabilone $1 \mathrm{mg}$ for 4 weeks vs nabilone associated to exposure and response prevention (ERP) therapy for 4 weeks on medication-free adults diagnosed with OCD. The study, to the best of our knowledge, is still not available on a peer-reviewed journal, but its results are reported on the clinicaltrials.gov website. According to these available data, 11 OCD patients have been recruited and divided in the two groups. None of the patients reported major side effects and only 3 patients reported anxiety as side effect. In the reported results the nabilone "alone" group reported a mean Y-BOCS score reduction of 2.5 points after 4 weeks of treatment while the nabilone+ERP reported a mean Y-BOCS score reduction of 11.2 points. Of course, we need to see the entire study results and statistical analysis in order to draw any conclusions.

\section{Psilocybin}

Psychedelic agents have gained a lot of attention in psychiatry after several investigations showed their putative improvement effects on depression, anxiety, addictions, and OCD, as we will see. ${ }^{120}$ Psychedelic agents usually act as serotonin $2 \mathrm{~A}$ receptor agonists and recently several preclinical studies highlighted their role in modulating the immune system by inducing an anti-inflammatory effect. ${ }^{120}$ Psilocybin, a potent $5-\mathrm{HT}_{1 \mathrm{~A}}$ and $5-\mathrm{HT}_{2 \mathrm{~A} / 2 \mathrm{C}}$ agonist, is one of the most studied compounds in this category of drugs. A small series of case reports suggested some putative beneficial effects of psychedelic agents on OCD patients since the early nineties. ${ }^{121}$ To the best of our knowledge, there is only one available open trial in the current literature. In 2006, an early small open trial assessed the acute effect of several different doses of psilocybin on OCD patients. ${ }^{122}$ Results of this study showed that all patients reported a marked reduction of OCD symptoms at some point during the 24 hours of the study. Psilocybin was well tolerated by almost all patients and only 1 out of the 9 subjects experienced transient hypertension non-related to anxiety or somatic symptoms. ${ }^{122}$

Interestingly, Yale University has now an ongoing trial on psilocybin for OCD. The study is a double-blind controlled trial that will involve 30 patients. Patients will be randomized to receive psilocybin $(0.25 \mathrm{mg} / \mathrm{kg})$ or the 
active comparator niacin $(250 \mathrm{mg})$. According to clinicaltrial.gov (last update mid-September 2020), the trial in still is the recruiting phase.

\section{Troriluzole (BHV-4I57)}

Troriluzole is a precursor of riluzole and, as this latter, is a glutamate modulator. Specifically, it reduces the synaptic levels of glutamate by augmenting the expression and function of the glial glutamate transporters (ie, EAAT2) responsible for glutamate synaptic clearance.

Phase 2-3 clinical trials are now investigating troriluzole as a treatment for Alzheimer's disease and spinocerebellar ataxia. According to clinicaltrials.gov register (mid-September 2020), there is a phase $2-3$ controlled trial sponsored by the Biohaven Pharmaceuticals, Inc., assessing its efficacy on treatment-resistant OCD patients. The trial is active but not recruiting.

\section{Nitrous Oxide Gas}

Nitrous oxide is a colorless and nearly odorless anesthetic gas. It is often used for surgical anesthesia in association with other agents, since it is one of the weakest anesthetic drugs. It has a low blood-gas solubility, which means a rapid on- and offset of actions; therefore, patients usually completely recover within a few minutes. Moreover, it is not metabolized and its uptake and elimination are via the lungs. ${ }^{123}$ Nitrous oxide's mechanism of action is supposed to be complex but mostly related to glutamatergic modulation. Indeed, it has an inhibitory action on both NMDA, AMPA, and kainite receptors, and it has an antagonist action on low voltage-activated calcium channels (LVA, T-type), and certain nicotinic acetylcholine receptors and potassium channels (TREK-1). ${ }^{123}$ Nitrous oxide is widely considered as very tolerable and safe (main side effects are nausea and vomiting, headaches, dizziness, and euphoria). ${ }^{123}$ Due to its anti-glutamatergic effect (as is the case for ketamine), it has been tested in treatmentresistant depressed patients. A recent randomized controlled trial showed that nitrous oxide significantly improved depression symptoms compared to placebo at 2 hours and after 24 hours from its administration. ${ }^{124}$ In this trial, no serious adverse events occurred; all adverse events were brief and of mild to moderate severity. ${ }^{124}$

As is the case for ketamine (firstly investigated in depression and subsequently in OCD), nitrous oxide has now gained attention also in the OCD field (mainly for its anti-glutamatergic effects). According to the register of clinicaltrials.gov register (mid-September 2020), a phase
2 double-blind controlled trial at the Stanford University is ongoing (not yet recruiting). This study seeks to explore whether a single inhalation of nitrous oxide gas may bring about rapid symptom relief in OCD. Nitrogen is used as active comparator.

\section{Rituximab}

Rituximab is a monoclonal antibody that binds the surface protein CD-20, widely expressed on B-lymphocyte. It triggers cell death and it has been used in the last 20 years for several CD20-expressing lymphoid malignancies. ${ }^{125}$ It is administered intravenously. Due to its positive effects on autoimmune and dys-immunological diseases, it is gained attention also for psychiatric disorders with a probable immunological etiology. Given the overmentioned evidence about a possible role of inflammation in OCD pathophysiology, rituximab is now under consideration for its use in OCD patients. According to the register of clinicaltrials.gov (midSeptember 2020), an open trial for treatment-resistant OCD patients is ongoing (and in a recruiting phase) in Sweden.

\section{Naproxen and Immunoglobulins for PANS/PANDAS}

As mentioned in the previous sections, a subset of pediatric-onset OCD is considered to be related to autoimmune phenomena (probably generated by a cross-reactivity between gangliosides in basal ganglia neurons with the GABHS and/or other agents cell). In this perspective, both anti-inflammatory agents and immunoglobulins gained much attention in the last years.

Based on the register of clinicaltrials.gov (mid-September 2020), there are two trials in an active phase, investigating these treatment approaches for this special population. The first is a multisite open-label trial (in the active-not recruiting stage) investigating the use of intravenous immunoglobulins (IVIG) at a dose of $1 \mathrm{~g} / \mathrm{Kg} /$ body weight given every 3 weeks for 6 infusions in pediatric subjects ages 4-16 years with moderate to severe PANS. The second is a double-blind placebo-controlled trial of Naproxen Sodium, a nonsteroidal antiinflammatory drug (NSAID) (a non-selective COX-1 and 2 inhibitor) given to participants diagnosed with Pediatric Autoimmune Neuropsychiatric Disorder Associated with Streptococcal infections (PANDAS).

\section{Other Agents Under Investigations}

Ondansetron, a serotonin $5 \mathrm{HT}_{3}$ receptor antagonist, usually prescribed to prevent nausea and vomiting, has been 
investigated in OCD. Some promising results have been found (for a review see ${ }^{126}$ ). However, a double-blind placebocontrolled trial of low daily dosages of ondansetron $(0.5$ and $0.75 \mathrm{mg}$ ) in a relatively large sample was negative. ${ }^{115}$ Now, a double-blind placebo-controlled trial with higher ondansetron doses on tic-related OCD patients is currently underway (clinicaltrials.gov, mid-September 2020).

Pregabalin, a gamma-aminobutyric acid analog, modulates calcium channels and has been approved for its use in epilepsy, neuropathic pain, fibromyalgia, and generalized anxiety disorder. Anecdotal reports showed some efficacy of pregabalin for OCD and a recent placebocontrolled randomized trial showed positive results respect to placebo in a dose range between 75 and $225 \mathrm{mg} .^{127}$ A randomized controlled trial at the McMaster University in Canada investigated the effects of pregabalin in a flexible dose up to $600 \mathrm{mg}$ for 8 weeks as an addition to SRIs treatment in resistant OCD. According to clinicaltrils.gov (last update mid-September 2020), the trial has concluded, but results are still not provided and, to the best of our knowledge, there are not available publications yet.

\section{Conclusions}

Treatment-resistance is a frequent condition for obsessivecompulsive disorder (OCD). More than a decade of investigations on augmentations strategies to serotonergic drugs, indicated antidopaminergic agents as the first choice for SRIs resistant patients. However, antidopaminergics seem to work only for one-third of patients and none of them have been officially approved for OCD.

On the other hand, over the last years OCD pathophysiology studies looked beyond serotonin and dopamine, and a role for glutamate and inflammation clearly emerged. This discovery has led to a large effort in the investigation of glutamatergic and anti-inflammatory agents. Results on anti-glutamatergic agents seem promising but still inconclusive. On the other hand, probiotic interventions (considered to modulate the immune systems and the brain activity) are gaining attention in several psychiatric fields but are still in their infancy in the OCD field. Research for new treatment approaches for OCD is moving forward, and more than one hundred interventional trials are ongoing around the world. While the vast majority of these trials involve neuromodulation and new psychotherapeutic approaches, only a small proportion (around 20\%) involve the investigation of new pharmacological approaches. Most of these are glutamatergic modulators and/or immunomodulators (troriluzole, nitrous oxide, rituximab, naproxen, and immunoglobulins). COMT inhibitors (tolcapone), endocannabinoid modulators (nabilone), and psychedelic agents (psilocybin) represent "new" pharmacological approaches for OCD.

However, in our opinion, more than discovering "new" agents, the goal for OCD pharmacological research in future years should be the application of a precision-medicine approach to OCD treatment. In other words, the imperative should be to individualize OCD treatments and find biomarkers in order to predict the treatment-response and in order to develop treatment approaches that are sub-type specific (both in terms of symptom dimensions and comorbidity patterns), phase specific (in a clinical staging perspective), multimodal and sequential, and, more importantly, dimensional.

\section{Disclosure}

The authors report no conflicts of interest for this work.

\section{References}

1. Ruscio AM, Stein DJ, Chiu WT, Kessler RC. The epidemiology of obsessive-compulsive disorder in the national comorbidity survey replication. Mol Psychiatry. 2010;15(1):53-63. doi:10.1038/ mp. 2008.94

2. Volavka J, Neziroglu F, Yaryura-Tobias JA. Clomipramine and imipramine in obsessive-compulsive disorder. Psychiatry Res. 1985;14(1):85-93. doi:10.1016/0165-1781(85)90092-7

3. Fineberg NA, Reghunandanan S, Simpson HB, et al. Obsessivecompulsive disorder (OCD): practical strategies for pharmacological and somatic treatment in adults. Psychiatry Res. 2015;227 (1):114-125. doi:10.1016/j.psychres.2014.12.003

4. Skapinakis P, Caldwell DM, Hollingworth W, et al. Pharmacological and psychotherapeutic interventions for management of obsessive-compulsive disorder in adults: a systematic review and network meta-analysis. Lancet Psychiatry. 2016;3 (8):730-739. doi:10.1016/S2215-0366(16)30069-4

5. Pallanti S, Grassi G, Cantisani A. Emerging drugs to treat obsessive-compulsive disorder. Expert Opin Emerg Drugs. 2014;19(1):67-77. doi:10.1517/14728214.2014.875157

6. Pallanti S, Hollander E, Bienstock C, et al. Treatment non-response in OCD: methodological issues and operational definitions. Int J Neuropsychopharmacol. 2002;5(2):181-191. doi:10.1017/ S1461145702002900

7. Grassi G, Pallanti S. Current and up-and-coming pharmacotherapy for obsessive-compulsive disorder in adults. Expert Opin Pharmacother. 2018;19(14):1541-1550. doi:10.1080/14656566. 2018.1528230

8. Zhou DD, Zhou XX, Lv Z, et al. Comparative efficacy and tolerability of antipsychotics as augmentations in adults with treatment-resistant obsessive-compulsive disorder: a network meta-analysis. J Psychiatr Res. 2019;111:51-58. doi:10.1016/j. jpsychires.2019.01.014

9. Chakrabarty K, Bhattacharyya S, Christopher R, Khanna S. Glutamatergic dysfunction in OCD. Neuropsychopharmacology. 2005;30(9):1735-1740. doi:10.1038/sj.npp.1300733

10. Bhattacharyya S, Khanna S, Chakrabarty K, Mahadevan A, Christopher R, Shankar SK. Anti-brain autoantibodies and altered excitatory neurotransmitters in obsessive-compulsive disorder. Neuropsychopharmacology. 2009;34(12):2489-2496. doi:10.1038/ npp.2009.77 
11. Yücel M, Wood SJ, Wellard RM, et al. Anterior cingulate glutamate-glutamine levels predict symptom severity in women with obsessive-compulsive disorder. Aust $N Z J$ Psychiatry. 2008;42(6):467-477. doi:10.1080/00048670802050546

12. Starck G, Ljungberg M, Nilsson $M$, et al. A $1 \mathrm{H}$ magnetic resonance spectroscopy study in adults with obsessive compulsive disorder: relationship between metabolite concentrations and symptom severity. J Neural Transm (Vienna). 2008;115(7):1051-1062. doi:10.1007/s00702-008-0045-4

13. Rosenberg DR, MacMaster FP, Keshavan MS, Fitzgerald KD, Stewart CM, Moore GJ. Decrease in caudate glutamatergic concentrations in pediatric obsessive-compulsive disorder patients taking paroxetine. J Am Acad Child Adolesc Psychiatry. 2000;39 (9):1096-1103. doi:10.1097/00004583-200009000-00008

14. Rosenberg DR, Mirza Y, Russell A, et al. Reduced anterior cingulate glutamatergic concentrations in childhood OCD and major depression versus healthy controls. $J$ Am Acad Child Adolesc Psychiatry. 2004;43(9):1146-1153. doi:10.1097/01.chi.00001328 12.44664.2d

15. O'Neill J, Piacentini J, Chang S, et al. Glutamate in pediatric obsessive-compulsive disorder and response to cognitive-behavioral therapy: randomized clinical trial. Neuropsychopharmacology. 2017;42(12):2414-2422. doi:10.1038/npp.2017.77

16. Giménez M, Cano M, Martínez-Zalacaín I, et al. Is glutamate associated with fear extinction and cognitive behavior therapy outcome in OCD? A pilot study [published online ahead of print, 2019 Aug 20]. Eur Arch Psychiatry Clin Neurosci. 2019. doi:10.1007/ s00406-019-01056-3

17. Rajendram R, Kronenberg S, Burton CL, Arnold PD. Glutamate genetics in obsessive-compulsive disorder: a review. $J$ Can Acad Child Adolesc Psychiatry. 2017;26(3):205-213.

18. Pittenger C. Glutamatergic agents for OCD and related disorders. Curr Treat Options Psychiatry. 2015;2(3):271-283. doi:10.1007/ s40501-015-0051-8

19. Marinova Z, Chuang DM, Fineberg N. Glutamate-modulating drugs as a potential therapeutic strategy in obsessive-compulsive disorder. Curr Neuropharmacol. 2017;15(7):977-995. doi:10.2174/ 1570159X15666170320104237

20. Molero P, Ramos-Quiroga JA, Martin-Santos R, Calvo-Sánchez E, Gutiérrez-Rojas L, Meana JJ. Antidepressant efficacy and tolerability of ketamine and esketamine: a critical review. CNS Drugs. 2018;32(5):411-420. doi:10.1007/s40263-018-0519-3

21. Rodriguez CI, Kegeles LS, Flood P, Simpson HB. Rapid resolution of obsessions after an infusion of intravenous ketamine in a patient with treatment-resistant obsessive-compulsive disorder. $J$ Clin Psychiatry. 2011;72(4):567-569. doi:10.4088/JCP.10106653

22. Bloch MH, Wasylink S, Landeros-Weisenberger A, et al. Effects of ketamine in treatment-refractory obsessive-compulsive disorder. Biol Psychiatry. 2012;72(11):964-970. doi:10.1016/j.biopsych.2012.05.028

23. Niciu MJ, Grunschel BD, Corlett PR, Pittenger C, Bloch MH. Two cases of delayed-onset suicidal ideation, dysphoria and anxiety after ketamine infusion in patients with obsessive-compulsive disorder and a history of major depressive disorder. J Psychopharmacol. 2013;27 (7):651-654. doi:10.1177/0269881113486718

24. Rodriguez CI, Kegeles LS, Levinson A, et al. Randomized controlled crossover trial of ketamine in obsessive-compulsive disorder: proof-ofconcept. Neuropsychopharmacology. 2013;38(12):2475-2483. doi:10. 1038/npp.2013.150

25. Rodriguez CI, Kegeles LS, Levinson A, et al. In vivo effects of ketamine on glutamate-glutamine and gamma-aminobutyric acid in obsessive-compulsive disorder: proof of concept. Psychiatry Res. 2015;233(2):141-147.

26. Rodriguez CI, Wheaton M, Zwerling J, et al. Can exposure-based CBT extend the effects of intravenous ketamine in obsessive-compulsive disorder? an open-label trial. J Clin Psychiatry. 2016;77(3):408-409. doi:10.4088/JCP. 15110138
27. Rodriguez CI, Levinson A, Zwerling J, Vermes D, Simpson HB. Open-Label trial on the effects of memantine in adults with obsessive-compulsive disorder after a single ketamine infusion. J Clin Psychiatry. 2016;77(5):688-689. doi:10.4088/JCP.15110 318

28. Moskal JR, Burch R, Burgdorf JS, et al. GLYX-13, an NMDA receptor glycine site functional partial agonist enhances cognition and produces antidepressant effects without the psychotomimetic side effects of NMDA receptor antagonists. Expert Opin Investig Drugs. 2014;23(2):243-254. doi:10.1517/13543784. 2014.852536

29. Rodriguez CI, Zwerling J, Kalanthroff E, et al. Effect of a novel NMDA receptor modulator, rapastinel (Formerly GLYX-13), in OCD: proof of concept. Am J Psychiatry. 2016;173(12):1239-1241.

30. Linkovski O, Shen $\mathrm{H}$, Zwerling J, et al. Effects of rapastinel (Formerly GLYX-13) on serum brain-derived neurotrophic factor in obsessive-compulsive disorder. J Clin Psychiatry. 2018;79 (1):17111824. doi:10.4088/JCP.17111824

31. Poyurovsky M, Weizman R, Weizman A, Koran L. Memantine for $\begin{array}{lllll}\text { treatment-resistant } & \text { OCD. } & A m & J & \text { Psychiatry. 2005;162 }\end{array}$ (11):2191-2192. doi:10.1176/appi.ajp.162.11.2191-a

32. Pasquini M, Biondi M. Memantine augmentation for refractory obsessive-compulsive disorder. Prog Neuropsychopharmacol Biol Psychiatry. 2006;30(6):1173-1175. doi:10.1016/j.pnpbp.2006.04.013

33. Hezel DM, Beattie K, Stewart SE. Memantine as an augmenting agent for severe pediatric OCD. Am J Psychiatry. 2009;166(2):237. doi:10.1176/appi.ajp.2008.08091427

34. Pekrul SR, Fitzgerald KD. Memantine Augmentation in a Down's Syndrome Adolescent with Treatment- Resistant ObsessiveCompulsive Disorder. J Child Adolesc Psychopharmacol. 2015;25 (7):593-595. doi:10.1089/cap.2015.0073

35. Aboujaoude E, Barry JJ, Gamel N. Memantine augmentation in treatment-resistant obsessive-compulsive disorder: an open-label trial. J Clin Psychopharmacol. 2009;29(1):51-55. doi:10.1097/ JCP.0b013e318192e9a4

36. Feusner JD, Kerwin L, Saxena S, Bystritsky A. Differential efficacy of memantine for obsessive-compulsive disorder vs. generalized anxiety disorder: an open-label trial. Psychopharmacol Bull. 2009;42(1):81-93.

37. Bakhla AK, Verma V, Soren S, Sarkhel S, Chaudhury S. An open-label trial of memantine in treatment-resistant obsessive-compulsive disorder. Ind Psychiatry J. 2013;22(2):149-152. doi:10.4103/0972-6748.132930

38. Stewart SE, Jenike EA, Hezel DM, et al. A single-blinded case-control study of memantine in severe obsessive-compulsive disorder. J Clin Psychopharmacol. 2010;30(1):34-39. doi:10.1097/ JCP.0b013e3181c856de

39. Haghighi M, Jahangard L, Mohammad-Beigi $\mathrm{H}$, et al. In a double-blind, randomized and placebo-controlled trial, adjuvant memantine improved symptoms in inpatients suffering from refractory obsessive-compulsive disorders (OCD). Psychopharmacology (Berl). 2013;228(4):633-640. doi:10.1007/s00213-013-3067-z

40. Ghaleiha A, Entezari N, Modabbernia A, et al. Memantine add-on in moderate to severe obsessive-compulsive disorder: randomized double-blind placebo-controlled study. J Psychiatr Res. 2013;47 (2):175-180. doi:10.1016/j.jpsychires.2012.09.015

41. Modarresi A, Sayyah M, Razooghi S, Eslami K, Javadi M, Kouti L. Memantine augmentation improves symptoms in serotonin reuptake inhibitor-refractory obsessive-compulsive disorder: a randomized controlled trial. Pharmacopsychiatry. 2018;51(6):263-269. doi:10.1055/ s-0043-120268

42. Modarresi A, Chaibakhsh S, Koulaeinejad N, Koupaei SR. A systematic review and meta-analysis: memantine augmentation in moderate to severe obsessive-compulsive disorder. Psychiatry Res. 2019;282:112602. doi:10.1016/j.psychres.2019.112602

43. Sansone RA, Sansone LA. Getting a Knack for NAC: N-AcetylCysteine. Innov Clin Neurosci. 2011;8(1):10-14. 
44. Grant JE, Odlaug BL, Kim SW. N-acetylcysteine, a glutamate modulator, in the treatment of trichotillomania: a double-blind, placebo-controlled study. Arch Gen Psychiatry. 2009;66 (7):756-763. doi:10.1001/archgenpsychiatry.2009.60

45. Grant JE, Chamberlain SR, Redden SA, Leppink EW, Odlaug BL, Kim SW. N-Acetylcysteine in the treatment of excoriation disorder: a randomized clinical trial. JAMA Psychiatry. 2016;73(5):490-496. doi:10.1001/jamapsychiatry.2016.0060

46. Costa DLC, Diniz JB, Requena G, et al. Randomized, double-blind, placebo-controlled trial of N-Acetylcysteine augmentation for treatment-resistant obsessive-compulsive disorder. $J$ Clin Psychiatry. 2017;78(7):e766-e773. doi:10.4088/JCP.16m11101

47. Sarris J, Oliver G, Camfield DA, et al. N-Acetyl Cysteine (NAC) in the treatment of obsessive-compulsive disorder: a 16-week, double-blind, randomised, placebo-controlled study. CNS Drugs. 2015;29(9):801-809. doi:10.1007/s40263-015-0272-9

48. Afshar $\mathrm{H}$, Roohafza $\mathrm{H}$, Mohammad-Beigi $\mathrm{H}$, et al. $\mathrm{N}$-acetylcysteine add-on treatment in refractory obsessive-compulsive disorder: a randomized, double-blind, placebo-controlled trial. $J$ Clin Psychopharmacol. 2012;32(6):797-803. doi:10.1097/JCP.0b013e $318272677 \mathrm{~d}$

49. Paydary K, Akamaloo A, Ahmadipour A, Pishgar F, Emamzadehfard S, Akhondzadeh S. N-acetylcysteine augmentation therapy for moderate-to-severe obsessive-compulsive disorder: randomized, double-blind, placebo-controlled trial. J Clin Pharm Ther. 2016;41(2):214-219. doi:10.1111/jcpt.12370

50. Ghanizadeh A, Mohammadi MR, Bahraini S, Keshavarzi Z, Firoozabadi A, Alavi Shoshtari A. Efficacy of N-Acetylcysteine augmentation on obsessive compulsive disorder: a multicenter randomized double blind placebo controlled clinical trial. Iran J Psychiatry. 2017;12(2):134-141.

51. Li F, Welling MC, Johnson JA, et al. N-acetylcysteine for pediatric obsessive-compulsive disorder: a small pilot study. J Child Adolesc Psychopharmacol. 2020;30(1):32-37. doi:10.1089/cap.2019.0041

52. Shen Y, He P, Fan -Y-Y, et al. Carnosine protects against permanent cerebral ischemia in histidine decarboxylase knockout mice by reducing glutamate excitotoxicity. Free Radic Biol Med. 2010;48 (5):727-735. doi:10.1016/j.freeradbiomed.2009.12.021

53. Rossignol DA. Novel and emerging treatments for autism spectrum disorders: a systematic review. Ann Clin Psychiatry. 2009;21 (4):213-236.

54. Szcześniak D, Budzeń S, Kopeć W, Rymaszewska J. Anserine and carnosine supplementation in the elderly: effects on cognitive functioning and physical capacity. Arch Gerontol Geriatr. 2014;59 (2):485-490. doi:10.1016/j.archger.2014.04.008

55. Chengappa KN, Turkin SR, DeSanti S, et al. A preliminary, randomized, double-blind, placebo-controlled trial of L-carnosine to improve cognition in schizophrenia. Schizophr Res. 2012;142(1-3):145-152. doi:10.1016/j.schres.2012.10.001

56. Arabzadeh S, Shahhossenie M, Mesgarpour B, et al. L-carnosine as an adjuvant to fluvoxamine in treatment of obsessive compulsive disorder: A randomized double-blind study. Hum Psychopharmacol. 2017;32(4):e2584. doi:10.1002/hup.2584

57. Leng Y, Fessler EB, Chuang DM. Neuroprotective effects of the mood stabilizer lamotrigine against glutamate excitotoxicity: roles of chromatin remodelling and Bcl-2 induction. Int J Neuropsychopharmacol. 2013;16(3):607-620. doi:10.1017/S1461145712000429

58. Bruno A, Micò U, Pandolfo G, et al. Lamotrigine augmentation of serotonin reuptake inhibitors in treatment-resistant obsessive-compulsive disorder: a double-blind, placebo-controlled study. J Psychopharmacol. 2012;26(11):1456-1462. doi:10.1177/ 0269881111431751

59. Khalkhali M, Aram S, Zarrabi H, Kafie M, Heidarzadeh A. Lamotrigine augmentation versus placebo in serotonin reuptake inhibitors-resistant obsessive-compulsive disorder: a randomized controlled trial. Iran J Psychiatry. 2016;11(2):104-114.
60. Poyurovsky M, Glick I, Koran LM. Lamotrigine augmentation in schizophrenia and schizoaffective patients with obsessive-compulsive symptoms. J Psychopharmacol. 2010;24(6):861-866. doi:10.1177/ 0269881108099215

61. Sharma V, Doobay M. Lamotrigine-induced obsessive-compulsive disorder in patients with bipolar disorder. CNS Spectr. 2019;24 (4):390-394. doi:10.1017/S1092852918001049

62. Mowla A, Khajeian AM, Sahraian A, Chohedri AH, Kashkoli F. Topiramate augmentation in resistant OCD: a double-blind placebo-controlled clinical trial. CNS Spectr. 2010;15 (11):613-617. doi:10.1017/S1092852912000065

63. Berlin HA, Koran LM, Jenike MA, et al. Double-blind, placebo-controlled trial of topiramate augmentation in treatment-resistant obsessive-compulsive disorder. J Clin Psychiatry. 2011;72(5):716-721. doi:10.4088/JCP.09m05266gre

64. Afshar H, Akuchekian S, Mahaky B, Zarean E. Topiramate augmentation in refractory obsessive-compulsive disorder: A randomized, double-blind, placebo-controlled trial. J Res Med Sci. 2014;19 (10):976-981.

65. Greenberg WM, Benedict MM, Doerfer J, et al. Adjunctive glycine in the treatment of obsessive-compulsive disorder in adults. $J$ Psychiatr Res. 2009;43(6):664-670. doi:10.1016/j.jpsychires.2008.10.007

66. de Leeuw AS, van Megen HJ, Kahn RS, Westenberg HG. d-cycloserine addition to exposure sessions in the treatment of patients with obsessive-compulsive disorder. Eur Psychiatry. 2017;40:38-44. doi:10.1016/j.eurpsy.2016.06.011

67. Storch EA, Wilhelm S, Sprich S, et al. Efficacy of augmentation of cognitive behavior therapy with weight-adjusted d-Cycloserine vs placebo in pediatric obsessive-compulsive disorder: a randomized clinical trial. JAMA Psychiatry. 2016;73(8):779-788. doi:10.1001/ jamapsychiatry.2016.1128

68. Mataix-Cols D, Fernández de la Cruz L, Monzani B, et al. D-Cycloserine augmentation of exposure-based cognitive behavior therapy for anxiety, obsessive-compulsive, and posttraumatic stress disorders: a systematic review and meta-analysis of individual participant data [published correction appears in JAMA Psychiatry. 2017 May 1;74(5):542]. JAMA Psychiatry. 2017;74 (5):501-510.

69. McGuire JF, Wu MS, Piacentini J, McCracken JT, Storch EA. A meta-analysis of D-Cycloserine in exposure-based treatment: moderators of treatment efficacy, response, and diagnostic remission. J Clin Psychiatry. 2017;78(2):196-206. doi:10.4088/JCP.15r10334

70. Wu PL, Tang HS, Lane HY, Tsai CA, Tsai GE. Sarcosine therapy for obsessive compulsive disorder: a prospective, open-label study. $J$ Clin Psychopharmacol. 2011;31(3):369-374. doi:10.1097/ JCP.0b013e3182189878

71. Grant PJ, Joseph LA, Farmer CA, et al. 12-week, placebo-controlled trial of add-on riluzole in the treatment of childhood-onset obsessive-compulsive disorder. Neuropsychopharmacology. 2014;39 (6):1453-1459.

72. Pittenger $\mathrm{C}$, Bloch $\mathrm{MH}$, Wasylink $\mathrm{S}$, et al. Riluzole augmentation in treatment-refractory obsessive-compulsive disorder: a pilot randomized placebo-controlled trial. J Clin Psychiatry. 2015;76 (8):1075-1084. doi:10.4088/JCP.14m09123

73. Emamzadehfard S, Kamaloo A, Paydary K, et al. Riluzole in augmentation of fluvoxamine for moderate to severe obsessive-compulsive disorder: randomized, double-blind, placebo-controlled study. Psychiatry Clin Neurosci. 2016;70(8):332-341. doi:10.1111/pcn. 12394

74. Khandaker GM, Dantzer R, Jones PB. Immunopsychiatry: important facts. Psychol Med. 2017;47(13):2229-2237.

75. Swedo SE, Leonard HL, Garvey M, et al. Pediatric autoimmune neuropsychiatric disorders associated with streptococcal infections: clinical description of the first 50 cases [published correction appears in Am J Psychiatry 1998 Apr;155(4):578]. Am J Psychiatry. 1998;155(2):264-271. 
76. Swedo SE, Leckman JF, Rose NR. From research subgroup to clinical syndrome: modifying the PANDAS criteria to describe PANS (pediatric acute-onset neuropsychiatric syndrome). Pediatr Ther. 2012;2:113. doi:10.4172/2161-0665.1000113

77. Chiarello F, Spitoni S, Hollander E, Matucci Cerinic M, Pallanti S. An expert opinion on PANDAS/PANS: highlights and controversies. Int $J$ Psychiatry Clin Pract. 2017;21(2):91-98. doi:10.1080/ 13651501.2017.1285941

78. Pearlman DM, Vora HS, Marquis BG, Najjar S, Dudley LA. Antibasal ganglia antibodies in primary obsessive-compulsive disorder: systematic review and meta-analysis. Br J Psychiatry. 2014;205 (1):8-16. doi:10.1192/bjp.bp.113.137018

79. Korostil M, Feinstein A. Anxiety disorders and their clinical correlates in multiple sclerosis patients. Mult Scler. 2007;13(1):67-72. doi:10.1177/1352458506071161

80. Bachen EA, Chesney MA, Criswell LA. Prevalence of mood and anxiety disorders in women with systemic lupus erythematosus. Arthritis Rheum. 2009;61(6):822-829. doi:10.1002/art.24519

81. Mataix-Cols D, Frans E, Pérez-Vigil A, et al. A total-population multigenerational family clustering study of autoimmune diseases in obsessive-compulsive disorder and Tourette's/chronic tic disorders. Mol Psychiatry. 2018;23(7):1652-1658. doi:10.1038/mp.2017.215

82. Cosco TD, Pillinger T, Emam $\mathrm{H}$, et al. Immune aberrations in obsessive-compulsive disorder: a systematic review and meta-analysis. Mol Neurobiol. 2019;56(7):4751-4759. doi:10. 1007/s12035-018-1409-x

83. Attwells S, Setiawan E, Wilson AA, et al. Inflammation in the neurocircuitry of obsessive-compulsive disorder. JAMA Psychiatry. 2017;74(8):833-840. doi:10.1001/jamapsychiatry.2017.1567

84. Burchi E, Pallanti S. Antibiotics for PANDAS? Limited evidence: review and putative mechanisms of action. Prim Care Companion CNS Disord. 2018;20(3):17r02232.

85. Spartz EJ, Freeman GM Jr, Brown K, Farhadian B, Thienemann M, Frankovich J. Course of neuropsychiatric symptoms after introduction and removal of nonsteroidal anti-inflammatory drugs: a pediatric observational study. J Child Adolesc Psychopharmacol. 2017;27 (7):652-659. doi:10.1089/cap.2016.0179

86. Kimura T, Iwase M, Kondo G, et al. Suppressive effect of selective cyclooxygenase-2 inhibitor on cytokine release in human neutrophils. Int Immunopharmacol. 2003;3(10-11):1519-1528. doi:10.1016/S1567-5769(03)00179-6

87. Strauss KI, Marini AM. Cyclooxygenase-2 inhibition protects cultured cerebellar granule neurons from glutamate-mediated cell death. $J$ Neurotrauma. 2002;19(5):627-638. doi:10.1089/0897 71502753754091

88. Abbasi SH, Hosseini F, Modabbernia A, Ashrafi M, Akhondzadeh S. Effect of celecoxib add-on treatment on symptoms and serum IL-6 concentrations in patients with major depressive disorder: randomized double-blind placebo-controlled study. J Affect Disord. 2012;141(2-3):308-314. doi:10.1016/j.jad.2012.03.033

89. Sayyah M, Boostani H, Pakseresht S, Malayeri A. A preliminary randomized double-blind clinical trial on the efficacy of celecoxib as an adjunct in the treatment of obsessive-compulsive disorder. Psychiatry Res. 2011;189(3):403-406. doi:10.1016/j.psychres.2011.01.019

90. Shalbafan M, Mohammadinejad P, Shariat SV, et al. Celecoxib as an adjuvant to fluvoxamine in moderate to severe obsessive-compulsive disorder: a double-blind, placebo-controlled, randomized trial. Pharmacopsychiatry. 2015;48(4-5):136-140. doi:10.1055/s-0035-1549929

91. Amantea D, Bagetta G. Drug repurposing for immune modulation in acute ischemic stroke. Curr Opin Pharmacol. 2016;26:124-130. doi:10.1016/j.coph.2015.11.006

92. Rodriguez CI, Bender J Jr, Marcus SM, Snape M, Rynn M, Simpson HB. Minocycline augmentation of pharmacotherapy in obsessive-compulsive disorder: an open-label trial. $J$ Clin Psychiatry. 2010;71(9):1247-1249. doi:10.4088/JCP.09105805blu
93. Esalatmanesh S, Abrishami Z, Zeinoddini A, et al. Minocycline combination therapy with fluvoxamine in moderate-to-severe obsessive-compulsive disorder: A placebo-controlled, double-blind, randomized trial. Psychiatry Clin Neurosci. 2016;70 (11):517-526. doi:10.1111/pen.12430

94. Turna J, Grosman Kaplan K, Anglin R, Van Ameringen M. "What's bugging the gut in OCD?" A review of the gut microbiome in obsessive-compulsive disorder. Depress Anxiety. 2016;33 (3):171-178. doi:10.1002/da.22454

95. Turna J, Grosman Kaplan K, Anglin R, et al. The gut microbiome and inflammation in obsessive-compulsive disorder patients compared to age- and sex-matched controls: a pilot study [published online ahead of print, 2020 Apr 20]. Acta Psychiatr Scand. 2020. doi: $10.1111 /$ acps. 13175

96. Naseribafrouei A, Hestad K, Avershina E, et al. Correlation between the human fecal microbiota and depression. Neurogastroenterol Motil. 2014;26(8):1155-1162. doi:10.1111/nmo.12378

97. Jiang H, Ling Z, Zhang Y, et al. Altered fecal microbiota composition in patients with major depressive disorder. Brain Behav Immun. 2015;48:186-194. doi:10.1016/j.bbi.2015.03.016

98. Collins SM, Surette M, Bercik P. The interplay between the intestinal microbiota and the brain. Nat Rev Microbiol. 2012;10 (11):735-742. doi:10.1038/nrmicro2876

99. Sudo N, Chida Y, Aiba Y, et al. Postnatal microbial colonization programs the hypothalamic-pituitary-adrenal system for stress response in mice. $J$ Physiol. 2004;558(Pt 1):263-275. doi:10. 1113/jphysiol.2004.063388

100. Thayer JF, Sternberg EM. Neural concomitants of immunity-focus on the vagus nerve. Neuroimage. 2009;47(3):908-910. doi:10. 1016/j.neuroimage.2009.05.058

101. Kamada N, Núñez G. Regulation of the immune system by the resident intestinal bacteria. Gastroenterology. 2014;146 (6):1477-1488. doi:10.1053/j.gastro.2014.01.060

102. Scheepers IM, Cryan JF, Bastiaanssen TFS, et al. Natural compulsive-like behaviour in the deer mouse (Peromyscus maniculatus bairdii) is associated with altered gut microbiota composition. Eur J Neurosci. 2020;51(6):1419-1427. doi:10.1111/ejn.14610

103. Quagliariello A, Del Chierico F, Russo A, et al. Gut microbiota profiling and gut-brain crosstalk in children affected by pediatric acute-onset neuropsychiatric syndrome and pediatric autoimmune neuropsychiatric disorders associated with streptococcal infections. Front Microbiol. 2018;9:675. doi:10.3389/fmicb.2018.00675

104. Kantak PA, Bobrow DN, Nyby JG. Obsessive-compulsive-like behaviors in house mice are attenuated by a probiotic (Lactobacillus rhamnosus GG). Behav Pharmacol. 2014;25 (1):71-79. doi:10.1097/FBP.0000000000000013

105. Messaoudi M, Violle N, Bisson JF, Desor D, Javelot H, Rougeot C. Beneficial psychological effects of a probiotic formulation (Lactobacillus helveticus R0052 and Bifidobacterium longum R0175) in healthy human volunteers. Gut Microbes. 2011;2 (4):256-261. doi:10.4161/gmic.2.4.16108

106. Axelrod J, Tomchick R. Enzymatic O-methylation of epinephrine and other catechols. J Biol Chem. 1958;233(3):702-705.

107. Jatana N, Apoorva N, Malik S, Sharma A, Latha N. Inhibitors of catechol-O-methyltransferase in the treatment of neurological disorders. Cent Nerv Syst Agents Med Chem. 2013;13 (3):166-194. doi:10.2174/1871524913666140109113341

108. Kumar P, Rai V. Catechol-O-methyltransferase gene Val158Met polymorphism and obsessive compulsive disorder susceptibility: a meta-analysis. Metab Brain Dis. 2020;35(2):241-251. doi:10.1007/ s11011-019-00495-0

109. Lachman HM, Papolos DF, Saito T, Yu YM, Szumlanski CL, Weinshilboum RM. Human catechol-O-methyltransferase pharmacogenetics: description of a functional polymorphism and its potential application to neuropsychiatric disorders. Pharmacogenetics. 1996;6(3):243-250. doi:10.1097/00008571-199606000-00007 
110. Lotta T, Vidgren J, Tilgmann C, et al. Kinetics of human soluble and membrane-bound catechol O-methyltransferase: a revised mechanism and description of the thermolabile variant of the enzyme. Biochemistry. 1995;34(13):4202-4210. doi:10.1021/bi00013a008

111. Chen J, Lipska BK, Halim N, et al. Functional analysis of genetic variation in catechol-O-methyltransferase (COMT): effects on mRNA, protein, and enzyme activity in postmortem human brain [published correction appears in Am J Hum Genet. 2005 Jun;76(6):1089]. Am J Hum Genet. 2004;75(5):807-821. doi:10.1086/425589

112. Wang Z, Xiao Z, Inslicht SS, et al. Low expression of catecholamine-O-methyl-transferase gene in obsessive-compulsive disorder. J Anxiety Disord. 2009;23(5):660-664. doi:10.1016/j. janxdis.2009.02.004

113. Taylor S. Association between COMT Val158Met and psychiatric disorders: A comprehensive meta-analysis. Am J Med Genet B Neuropsychiatr Genet. 2018;177(2):199-210. doi:10.1002/ajmg. b. 32556

114. Grassi G, Pallanti S, Righi L, et al. Think twice: impulsivity and decision making in obsessive-compulsive disorder. J Behav Addict. 2015;4(4):263-272. doi:10.1556/2006.4.2015.039

115. Fineberg NA, Hollander E, Pallanti S, et al. Clinical advances in obsessive-compulsive disorder: a position statement by the International College of Obsessive-Compulsive Spectrum Disorders. Int Clin Psychopharmacol. 2020;35(4):173-193.

116. Deleu D, Northway MG, Hanssens Y. Clinical pharmacokinetic and pharmacodynamic properties of drugs used in the treatment of Parkinson's disease. Clin Pharmacokinet. 2002;41(4):261-309. doi:10.2165/00003088-200241040-00003

117. Kayser RR, Snorrason I, Haney M, Lee FS, Simpson HB. The endocannabinoid system: a new treatment target for obsessive compulsive disorder? Cannabis Cannabinoid Res. 2019;4 (2):77-87. doi:10.1089/can.2018.0049
118. Lutz B, Marsicano G, Maldonado R, Hillard CJ. The endocannabinoid system in guarding against fear, anxiety and stress. Nat Rev Neurosci. 2015;16(12):705-718.

119. Szejko N, Fremer C, Müller-Vahl KR. Cannabis improves obsessive-compulsive disorder-case report and review of the literature. Front Psychiatry. 2020;11:681. doi:10.3389/fpsyt.2020.00681

120. Flanagan TW, Nichols CD. Psychedelics as anti-inflammatory agents. Int Rev Psychiatry. 2018;30(4):363-375. doi:10.1080/ 09540261.2018.1481827

121. Wilcox JA. Psilocybin and obsessive compulsive disorder. J Psychoactive Drugs. 2014;46(5):393-395. doi:10.1080/02791 072.2014 .963754

122. Moreno FA, Wiegand CB, Taitano EK, Delgado PL. Safety, tolerability, and efficacy of psilocybin in 9 patients with obsessive-compulsive disorder. J Clin Psychiatry. 2006;67 (11):1735-1740. doi:10.4088/JCP.v67n1110

123. Nagele P, Zorumski CF, Conway C. Exploring nitrous oxide as treatment of mood disorders: basic concepts. J Clin Psychopharmacol. 2018;38(2):144-148. doi:10.1097/JCP.0000000000000837

124. Nagele P, Duma A, Kopec $M$, et al. Nitrous oxide for treatment-resistant major depression: a proof-of-concept trial. Biol Psychiatry. 2015;78(1):10-18. doi:10.1016/j.biopsych.2014.11.016

125. Salles G, Barrett M, Foà R, Maurer J. Rituximab in B-Cell hematologic malignancies: a review of 20 years of clinical experience. $A d v$ Ther. 2017;34(10):2232-2273. doi:10.1007/s12325-017-0612-x

126. Serata D, Kotzalidis GD, Rapinesi C, et al. Are 5-HT3 antagonists effective in obsessive-compulsive disorder? A systematic review of literature. Hum Psychopharmacol. 2015;30(2):70-84. doi:10.1002/ hup. 2461

127. Mowla A, Ghaedsharaf M. Pregabalin augmentation for resistant obsessive-compulsive disorder: a double-blind placebo-controlled clinical trial. CNS Spectr. 2020;25(4):552-556. doi:10.1017/ S1092852919001500

\section{Publish your work in this journal}

The Journal of Experimental Pharmacology is an international, peerreviewed, open access journal publishing original research, reports, reviews and commentaries on all areas of laboratory and experimental pharmacology. The manuscript management system is completely online and includes a very quick and fair peer-review system. Visit http://www.dovepress.com/testimonials.php to read real quotes from published authors. 